\title{
THE A TO Z OF HEALTH PROMOTION
}

\author{
Glenn Laverack (PhD) \\ Honorary Professor, \\ Unit of Health Promotion Research \\ University of Southern Denmark \\ Esbjerg \\ Denmark \\ glaverack@health.sdu.dk
}

\section{Abstract}

This article review main components of health promotion. It explains details requirements for a successful health promotion. The $A$ to $Z$ of health promotion introduced by Glenn Laverack offers a comprehensive model on which the design is practice-based, within the appropriate practice context, emphasise on the balance relationship between practitioners and program's clients, and focus on the empowering purpose in mind. The health promotion guide consists of 72 main entries; covers a broad range of practical knowledge, theories, approaches, practices and issues related to health promotion. For the purpose of illustration, the author picked seven of the entries; namely advocacy, behaviour change communication, community, empowerment, network, peer education and zero non-zero sum to demonstrate ways in which each of the entry guide the readers or practitioners when doing the health promotion programmes.

Keywords: A to Z, health promotion, model of health promotion, 72 entries 


\section{Introduction}

While there is no singularly accepted definition of health promotion, its operational purpose, formalised by both the Ottawa and Bangkok Charters, is agreed to be 'enabling people to increase control over, and to improve, their health, and its determinants' (WHO, 1986; WHO, 2005). In practice, much of the work that health promoters do is intended to help others to increase their level of control over their lives, health and its determinants. The A to $Z$ of health promotion has been specifically written with this empowering purpose in mind.

Health promotion often includes the use of more than one model on which its practice is based, and this presents the challenge of how to apply the correct theory (the science) within the appropriate practice context (the art). Health promoters continually have to shift their attention between theory and practice and across the broader professional arena. As a consequence, it creates particular challenges such as linking theory and practice, identifying the evidence base, defining concepts and establishing guiding principles. A specific professional need that this book meets is to provide a comprehensive source of reference to better inform the application of the theory in the achievement of health promotion best practice.

Within health promotion, there is always some power relationship, primarily between the practitioner and their clients. Health promotion professionals are employed to deliver information, resources and services set within the design of an intervention, a project or a programme. The practitioner is employed by a government department, agency or government-funded Non-Governmental Organisation and is often seen as an external agent by their clients. Practitioners call themselves 'health promoters' or 'public health workers' while much more who look to the idea of health promotion occupy roles such as nurses, social workers and doctors. Their 'clients' cover the range of people with whom they work including patients, women, adolescents, men and other professional groups. The terms 'practitioner' and 'client' have been intentionally used in this book because they help to demonstrate the unbalanced power relationship that often exists in health promotion. 


\section{An Outline of the Book}

The $a$ to $z$ of health promotion is written by Dr Glenn Laverack, and was published by Palgrave Macmillan in 2014 (ISBN: 9781137350480). It is a 'onestop' source book covering a range of entries that apply to anyone working in health promotion or associated disciplines such as public health and nursing. The writing is purposefully accessible to undergraduates and practitioners, theoretically well informed and uses empirical research, case studies and other examples sourced from the author's experience. Additional material from the grey literature or systematically collected evidence by others, such as Internet sites and databases is all clearly cited and referenced to indicate the relative strength of the information that is presented.

Each of the 72 main entries (see Box 1) have been purposefully written to provide sufficient reference information on a particular subject or a placeholder heading to direct the reader to a populated entry. The book does not have to be read sequentially as the user can access any one entry or any combination of entries, separately. Other useful features include the use of systematic italicised cross-referencing embedded in the narrative and 'see also' references under each entry to aid navigability and encourage readers to move from one entry to another. A list of contents and a detailed index also assist ease of access along a pathway that reflects the readers own interests and needs. Each entry has a listing of up to 3 key texts, websites and further sources of information to encourage the reader to gain a more in-depth understanding of the subject area.

\footnotetext{
Box 1. The 72 main entries in the a to $z$ of health promotion

1 Advocacy, 2 Alliances, Partnerships and Coalitions, 3 Approaches, 4 Behaviour Change Communication, 5 Bottom-up and top-down, 6 Boycotts, 7 Civil society, 8 Community, 9 Community based intervention, 10 Community capacity building, 11 Competencies, 12 Conflict resolution, 13 Counselling and one to one communication, 14 Critical consciousness, 15 Declarations and statements, 16 Definition, 17 Determinants of health, 18 Disease prevention, 19 Empowerment, 20 Ethics, 21 Evaluation, 22 Evidence based, 23 Foundations, 24 Gender and health, 25 Global health, 26 Harm reduction, 27 Health activism, 28 Health and wellbeing, 29 Health education, 30 Health literacy, 31 Health Profiles, 32 Health protection, 33 Healthy public policy, 34 Health Social Movements, 35 Hegemonic power, 36 Hygiene promotion, 37 Individualism and health, 38 Information and Communication Technology, 39 Information, Education and Communication, 40 Injury prevention, 41 Lay epidemiology, 42 Leadership, 43 Leverage, 44 Life skills, 45 Lifespan approach, 46 Lifestyle approach, 47 Lobbying, 48 Marginalisation, 49 Media, 50 Mental health promotion, 51 Moral suasion, 52 Needs assessment, 53 Networks, 54 Parallel-tracking, 55 Patient empowerment, 56 Peer education, 57 Photo-voice, 58 Political, 59 Power, 60 Powerlessness, 61 Pressure groups, 62 Primary health care, 63 Public health, 64 Risk factors, 65 Salutogenesis, 66 Screening, 67 Selfhelp groups, 68 Settings, 69 Social justice, 70 Social marketing, 71 Theory and models, 72 Zero and NonZero-Sum.
} 
The reader firstly chooses an entry listed in the list of contents, or in the index of the book, that matches the term about which they wish to gain a better understanding. For example, the entry 'Theory and Models' provides the practitioner with a sound knowledge of the theoretical foundations of health promotion. Alternatively, the entry 'Social Marketing' will provide the practitioner with an understanding of a methodology commonly used in health promotion programmes. Each entry has been written to provide the reader with a precise definition, a theoretical and, where appropriate, a historical background. For entries with a practical purpose, some examples of application have been provided in a programme context. If the reader requires further information, they can simply follow the 'see also' references under each heading to aid navigability or consult one of the key texts, websites and further sources listed at the end of the entry.

\section{Examples of Key Entries in the Book}

To illustrate the practical application and usefulness of the book, the author presents seven entries from a to $z$ as follows: Advocacy; Behaviour Change Communication; Community; Empowerment; Networks; Peer Education; and Zero and non-zero-sum.

\section{Advocacy}

Advocacy involves people acting on behalf of themselves or behalf of others to argue a position and to influence the outcome of decisions. In health promotion practice, advocacy initiatives are usually started to support particular causes, interest groups and ideologies (Smithies \& Webster, 1998).

The Ottawa Charter for health promotion states that actions aim at making conditions favourable for better health through advocacy (WHO, 1986). Advocacy uses both direct and indirect actions and can include media campaigns, public speaking and research with the intention of influencing policy, resource allocation and decision making within political and social systems. 
Some of the key forms of advocacy include:

1) Health Advocacy supports and promotes health care rights as well as enhancing community health and policy initiatives, for example, the availability, safety and quality of care. It focuses on education and relies on expert knowledge rather than inserting lay knowledge into expert systems (Brown, Zavestoski, McCormick, Mayer, Morello-Frosch \& Gasior, 2004).

2) Media advocacy is the strategic use of the mass media as a resource to advance a social or public policy initiative and aims to influence the selection, framing and debate of specific topics by the mass media. The goal of media advocacy is to get the media's attention and to frame the problem and solution in an appropriate way, so that policy makers, politicians and the public understand the issue. Media advocacy targets the ways in which issues come to be regarded as newsworthy to help set the debate and to try to influence the boundaries within which it can take place (Wallack, Dorfman, Jernigan \& Makani, 1993).

3) Collective or mass advocacy occurs when groups and organisations campaign on issues that are important to their members and who then speak out for themselves or influence what others say in the campaign, for example, through protests (Loue, Lloyd \& O'Shea, 2003).

4) Peer advocacy occurs when a person agrees to act on behalf of another, for example, volunteers who are recruited to act in the name of service users at a citizens' advice bureau.

5) Self-advocacy occurs when individuals or groups, share the same concerns or act on their behalf.

6) Legal advocacy happens when a legally qualified person is employed to act on behalf of others as an advocate, solicitor or barrister (Smithies \& Webster, 1998).

In practice, the different forms of advocacy can overlap. For example, self-advocacy groups can play a significant role for supporting peer advocacy, and collective advocacy can support the efforts of self-advocacy groups. Action on Smoking and Health (ASH), for example, is the name of some autonomous advocacy groups throughout the world that has been successful in taking action against the risks associated with tobacco smoking. ASH does not blame smokers or condemn smoking but instead uses an evidence-based dual approach; information and networking and advocacy and campaigning. ASH is a campaigning health charity that also uses tactics for political influence 
through the creation of alliances and coalitions. ASH has had some success, for example, in 2007 it won its campaign for a total ban on smoking in enclosed public places in England including bars and private member's clubs, as well as cafés, restaurants, and workplaces. A similar ban is also in force in Scotland and Wales and a number of other European countries (ASH, 2012). ASH purposefully uses indirect strategies because its status as a charity creates a dependence on funding sources including from the government.

There is a real risk that advocating on behalf of others, especially the socially marginalised so that they are included into the economic mainstream, does not challenge the economic mainstream as being inherently socially marginalising. For some, advocacy is ineffectual as an approach, one that does not challenge those in authority to force them to make the system more equitable. Health promotion must do more than helping others to speak and act on their behalf through advocacy (Labonte \& Laverack, 2008). It is empowerment that enables others to take more control of their lives, usually through forcing social and political change. Strategies that include advocacy must therefore also use an empowerment approach for health promotion to achieve improvements in the lives and health of others.

\section{Behaviour Change Communication}

Behaviour Change Communication is an intervention to promote positive health behaviours that are appropriate to people's settings (UNDP, 2002).

A 'health behaviour' is any activity undertaken by an individual, regardless of actual or perceived health status, for the purpose of promoting, protecting or maintaining health, whether or not such behaviour is objectively effective towards that end. Almost every behaviour or activity by an individual has an impact on their health, and it is, therefore, useful to distinguish between behaviours which are purposefully adopted to promote or protect the health and those which may be utilised regardless of the consequences to health (WHO, 1998). Providing people with information and teaching them how to behave does not necessarily lead to a desirable change in their behaviour. However, when there is a supportive environment plus an efficient communication strategy, there is a greater chance of a beneficial change in the behaviour of the target group. 
Behaviour Change Communication has a close relation to information education and communication, health education and health communication. However, it is different from other instructional methods of communication because it is target specific and systematically considers the following in its design: The vulnerability/risk factor of the target group; The conflict and obstacles in the way to the desired change in behaviour; Type of message and communication media which can best reach the target group; Type of resources available and assessment of existing knowledge of the target group about the issue (UNDP, 2002).

The ideological foundation for a Behaviour Change Communication approach is based on the assumption that before individuals and communities can change their behaviours, they must first understand basic facts about a particular health issue, adopt fundamental attitudes, learn a set of skills and be given access to appropriate products and services. They must also perceive their environment as supporting their behaviour change and the maintenance of safe behaviours, as well as being supportive of seeking appropriate treatment for prevention, care and support, if necessary. This process has been identified as having a number of the main steps centred around the provision and acceptance of new information and skills including pre-knowledge, becoming more knowledgeable, having a positive attitude towards the new knowledge, intending to take action to change their behaviour, practising and advocating the behaviour (Corcoran, 2013).

Behaviour Change Communication has relied upon top-down, one directional method, such as the mass media and this may have contributed to the causes of the gap between knowledge and practice (UNICEF, 2001). For example, in Vietnam $99 \%$ of people interviewed nationally were found to be aware of the link between iodine deficiency and goitre following a mass media campaign. However, supplementary iodized salt intake in some regions, such as the Mekong Delta remained lower (68\%) than the national average intake (77\%) (National Iodine Deficiency Disorder Control Program, 2000).

Other causes of this gap include a reliance on didactic styles of communication, inadequate audience segmentation, inappropriate message content and inferior materials development. This can be prevented by employing strategies that create a two-way communication between the recipient and a 'significant other' source of information, for example, a family member or health professional. A two-way communication creates a dialogue in which barriers to resolving health problems can be identified, and actions to address the issue can be planned. To be effective, Behaviour Change 
Communication must, therefore, use strategies that involve the development of a dialogue with the intended target group or individual including one to one communication, self-help groups, health literacy and interactive Information and Communication Technologies.

\section{Community}

It is important to think beyond the conventional view of a community as a place where people live, for example, neighbourhood, because these are often just an aggregate of non-connected people. Communities have both a social and a geographic characteristic and consist of various individuals with dynamic relations that sometimes organise into groups to take action towards achieving shared goals (Laverack, 2004).

As a working 'rule of thumb' community will have the following characteristics:

1) A spatial dimension that is, a place or locale;

2) Non-spatial dimensions that involve people who otherwise make up heterogeneous and disparate groups;

3) Social interactions that are dynamic and bind people into relationships;

4) The identification of shared needs and concerns (Laverack, 2004: 46).

Within the geographic dimensions of 'community', multiple non-spatial communities exist, and individuals may belong to several different 'interest' groups at the same time. Interest groups exist as a legitimate means by which people can find a 'voice' and can participate in pursuing their interests and concerns. Interest groups can be organised around a variety of social activities or can address a local and shared concern, for example, poor access to public transport. The diversity of individuals and groups within a community can create problems about the selection of representation by its members (Zakus $\&$ Lysack, 1998). Practitioners try to work with the 'legitimate' representatives of a community and to avoid the establishment of a dominant minority that can dictate community issues based only on their concerns and not on those of the majority. Practitioners need to carefully consider if the representatives of a community are in fact supported by its members and that they are not merely acting out of self-interest and self-gain. 
Goodman, Speers, McLeroy, Fawcett, Kegler, Parker, Rathgeb, Smith, Sterling and Wallerstein (1998) argue that a sense of community can be strengthened through a connection with or an understanding of its history. This is made up of events, people and experiences involving previous economic, political and socio-cultural contexts. Knowledge of the historical context of the community can help identify potential barriers such as experiences of conflict or feelings of helplessness and provide a better chance of affecting change, than those that do not have access to this information.

With the advent of online communities, new types of computerised tools have been developed to aid user participation. Information and communication technology has removed the physical barriers to communication, for example, people can participate on-line in discussions that are classified by topic, each with many conversational threads from across the globe. Online communities, like traditional forms of community, consist of a diverse group of people who participate in virtual spaces with little social context and member identity. Social media can encourage communication by enabling participants to find others with whom they only share interests and by providing a means to contact them. This facilitates social interactions in online communities and promotes communication by creating chat spaces that allow the participants to perceive the number of people present and the level of their activity, just as they would in a room in the offline world. The internet has helped to promote 'global communities' and 'digital cities' by building arenas in which people can interact, share knowledge, experience, and mutual interests. However, online activity is still limited to those who are computer literate and have access to a computer and the internet, and this can exclude many people (Nomura \& Ishida, 2003).

\section{Empowerment}

Empowerment in the broadest sense is "...the process by which disadvantaged people work together to increase control over events that determine their lives" (Werner, 1988: 1).

Most definitions of empowerment give the term a similarly positive value and have been widely developed in western and uniquely American value systems, which place a strong emphasis on individual and community responsibility (Minkler, 1989). They embody the notion that empowerment must come from within an individual, group or community and cannot be given to them. It is through the process of community empowerment that people are best able to achieve the broader social and political change that is necessary 
to improve their lives and health. To provide clarity to this concept, it is useful to consider the different levels of community empowerment. Christopher Rissel (1994) includes a heightened or increased level of psychological empowerment as a part of community empowerment and argues that it includes "...a political action component in which members have actively participated and the achievement of some redistribution of resources or decision-making favourable to the community or group in question"(p.1).

Israel, Checkoway, Schultz and Zimmerman (1994) similarly identify the psychological and political action as two levels of community empowerment but include a third, and intermediary level between them, that of organisational empowerment. Their analysis of this level draws heavily from democratic management theory. An empowered organisation is one that is democratically managed, and its members share information and control over decisions and are involved in the design, implementation and monitoring of efforts toward goals defined by group consensus. It is an essential link between empowered individuals and effective political action and is similar to the structure of many pressure groups and social movements.

Community empowerment includes personal empowerment, family empowerment, organisational empowerment and broader social and political changes. It is a dynamic process involving continual shifts in personal empowerment and changes in power relations between different social groups and decision makers in the broader society (Laverack, 2004). Community empowerment outcomes include the redistribution of resources, a decrease in powerlessness or success in achieving social and political change. But it is a process that it is most consistently viewed in the literature, for example, "...a social action process that promotes participation of people, organizations and communities towards the goals of increased individual and community control, political efficacy, improved quality of life and social justice" (Wallerstein, 1992:1).

As a process, community empowerment is best considered as a continuum representing progressively more organised and broadly-based forms of collective action (Laverack, 1999: 92). The community empowerment continuum is illustrated by Figure 1 . 


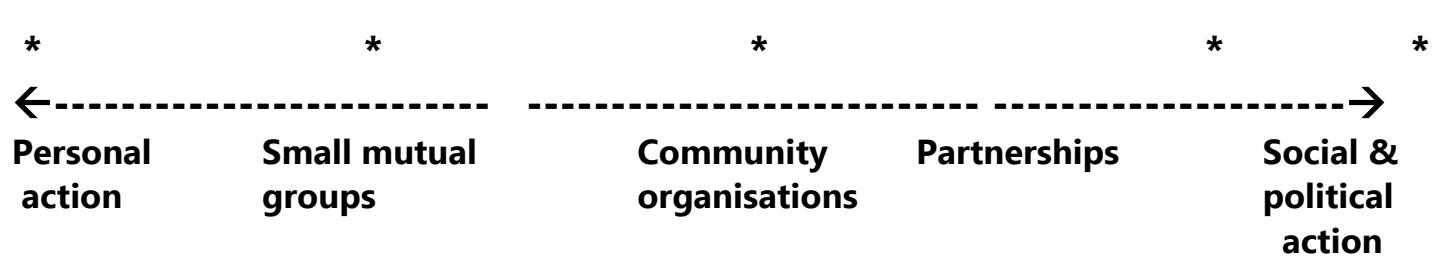

Figure 1: The Community Empowerment Continuum

Each point on the continuum can be viewed as a progression toward the goals of social and political action. The groups and organisations that develop in the process have their own dynamics, they may flourish for a time then fade away, for reasons as much to do with changes in the community as with a lack of broader political or financial support. The weakness of the continuum approach is that it offers a simple, linear interpretation of what can be a more fluid and complex process.

Nonetheless, the continuum provides a valuable tool to help practitioners to understand how they can become involved in empowering approaches. The role of the practitioner is as a 'facilitator' to support and enable individuals, groups and communities to progress along the continuum. The desired outcomes are actions that bring about social and political change. Social change refers to societal norms, beliefs and behaviours that have an influence on the community. In turn, the political change refers to policy, legislation and governance that have a direct influence on people's health (Labonte \& Laverack, 2008).

Gaining power to influence economic, political, social and ideological change will inevitably involve the community in a struggle with those already holding power. The role of the health promoting agency, at the request of the community, is to build capacity, provide resources and to help to empower individuals and organisations. Working in empowering ways is also a political activity because the structures of power-over, of bureaucracy and authority that create powerlessness remain dominant. The role of health promotion is to strive to help others to challenge these circumstances.

\section{Networks}

Networks set a context within groups, formal organisations, and institutions for those who work in or are served by them, which, in turn, affects what people do, how they feel, and what happens to them (Wright, 1997).

A network is a structure of relationships linking social actors (Wasserman \& Faust, 1994) that in turn are the building blocks of human 
experience, mapping the connections that individuals have to one another (Pescosolido,1991). Social structures are not based therefore on categorizations such as age, gender or race but on the actual nature of the social contacts that individuals have and the impact on people's lives (White, 1992).

A health network is a structure of relationships, both personal and professional, through which individuals maintain and receive emotional support, resources, services and information for the improvement of their health and wellbeing. These networks can be an indication of related health behaviour, for example, the biological and behavioural traits associated with obesity appear to be spread through social ties. People who experience the weight gain of others in their social networks may then more readily accept weight gain in themselves.

Moreover, social distance was more important than geographic distance within networks, and there was an important role for a process involving the induction and person-to-person spread of obesity. Peer support interventions that allow for a modification of people's social networks are therefore more successful than those that do not. Social networks can also be used to spread positive health behaviours because people's perceptions of their risk of illness may depend on the people around them (Christakis \& Fowler, 2007).

In a fundamental way, our health is a reflection of the quality of our relationships with one another, and social networks offer many people the opportunity to strengthen the level of social capital in their lives. Social capital in the form of trust, social norms of reciprocity and cooperation resides in relationships, not individuals, and therefore in the social networks in which they participate.

Active participation within social networks builds the trust and cohesiveness between people that are important to mobilise and create the resources necessary to support collective action. Social capital is a feature of social organisation such as networks, trust, facilitate coordination and collaboration. Individuals invest in and use the resources embedded in social networks because they expect returns of some sort although resources are not equally available to all persons and are differentially distributed across groups in society (Lin, 2000). 
The Patients Association (UK), for example, is a network about common patient issues for better information and support. The most frequent complaints received by the Patients Association are poor communication; toileting; pain relief; nutrition and hydration. The Association addresses the shared concerns of its members including the 'duty to refer', for patients to be able to trust that their doctors are making sure they are getting access to the best treatment. Access to information is the best way to ensure this is happening and patient support groups are ideally placed to provide this service. Doctors cannot be experts in all fields, and so it is important for them to be able to direct patients to other organisations which have the expertise. Doctors can then actively support patients in finding support groups and networks that could help them with managing their condition (Patients Association, 2011).

Networks also have some features that are particularly relevant to professional groups such as health promotion, whose functions rely on the interactions between its members. Social relationships underpin network activity with a strong sense of professional identity and solidarity and offer individuals and organisations the opportunity to access complementary resources and expertise. However, networks require significant investment for their establishment and maintenance and may therefore absorb rather than unlock resources, at least in the short term. Networks require a non-hierarchical management style which allows interaction between its members and this is in contrast to the bureaucratic and hierarchical style of much of the health promotion sector.

\section{Peer education}

Peer Education is an approach in which people are supported to promote health-enhancing change among their peers. Rather than health professionals educating members of the public, lay persons are felt to be in the best position to encourage healthy behaviour to each other (Kelly, St Lawrence, Stevenson, Hauth, Kalichman, Diaz, Brasfield, Koob \& Morgan, 1992).

In health promotion, peer education is usually initiated by practitioners who recruit members of the 'target' community to serve as educators. Peer educators are typically about the same age as the group with whom they are working. The recruited peer educators are trained in relevant health information and communication skills and then engage their peers in conversations about the issue of concern, seeking to promote healthenhancing behaviour change. The intention is that familiar people, giving locally-relevant and meaningful suggestions, in a local language and taking 
account of the local context, will be more likely to promote health. They may work alongside the health promoter, run educational activities on their own, or take the lead in organising and implementing activities. Youth peer educators, for example, have shown in some cases to be more effective than adults in establishing norms and in changing attitudes related to sexual behaviour (UNICEF, 2013).

Peer education has become very popular in the field of HIV prevention, especially involving young people, sex workers, men who have sex with men and intravenous drug users. Peer education is also associated with efforts to prevent tobacco, drug or alcohol use among young people, teenage pregnancy and homelessness. The Alcohol and Substance Abuse Prevention (ASAP) programme, for example, sought to empower youth from high-risk populations to make healthier choices in their lives and to play active political and social roles in society. The programme approach brought small groups of high school students together in a hospital emergency centre and a county detention centre to interact with patients and detainees who had drug-related problems. Youth were able to share experiences directly with the inmates and with their peers to learn through asking questions and exploring problems at different levels. The students formed a 'Students Against Drunk Driving (SADD)' chapter when one of the students was killed in a drink-related driving accident. Gradually the students began to take a leadership role and organised meetings and events to raise the issues of drug abuse and drink driving in local meetings. The students had a statistically significant increase in self-reported perception of the risks involving drinking and substance abuse as compared to the control group, which showed a significant drop in perception (Wallerstein \& Bernstein, 1988).

Despite its popularity, the evidence about peer education is mixed, seemingly working in some contexts but not in others. In a study that comparing peer education among sex workers in India and South Africa, for example, found that the more successful Indian group benefited from a supportive social and political context, and a more efficient community development ethos, rather than the biomedical focus of the South African intervention (Cornish \& Campbell, 2009).

Peer education should be seen as a strategy that can be used alongside other strategies in a broader health promotion approach or community-wide effort. For example, it has been used effectively to complement skills-based health education on condom promotion and youth-friendly health services (UNICEF, 2013). 


\section{Zero and Non-Zero-Sum}

A zero-sum situation exists when one can only possess an $x$ amount of power to the extent that someone else has an absence of an equivalent amount of power (Laverack, 2004: 34).

Power is often interpreted as a finite entity in which one person, group or organisation has influence and mastery over others. Zero-sum power creates a 'win/lose' situation. My power over you, plus your absence of that power, equals zero (thus the term, 'zero-sum'). I win, and you lose. For you to gain power, you must seize it from me. If you can, you win, and I lose. It is important to understand that power has to be gained or seized by those who what to achieve it, by raising the position of one person or group, while simultaneously lowering it for another person or group (Laverack, 2004).

Zero-sum power is often used in association with economic or political accounts where power is equated to wealth and income, authority and status and is particularly dominant in western societies. At any one time, there will be only so much wealth possessed within a society. This distribution and the decision-making authority that goes with it is zero-sum. One has authority or social status by others not having it. There is a degree of flexibility here, however, since someone may have authority or status in one situation, relative to others, but not in another.

At the same time, there are dominant social forms of status or privilege, such as class, gender, education, ethnic background, age and even physical ability or sexual preference, which tend to structure power-over relations in most social situations. For example, an immigrant man may hold the position of a community leader or hereditary chief within his ethnic community, but within his workplace have only a low-paying menial job with little responsibility or status.

In the same way, the beneficiaries of a health promotion programme may bring with them lots of power in the form of authority and control within their community. These individuals can be a significant factor in enabling others to take control of the influences on their lives and health such as using local leaders to manage programmes assisted by 'technical experts' to improve the skills and competencies of these individuals. The role of health promotion in this zero-sum construction of power is to assist others to gain power, meaning here more control over resources or decision-making that influence their health, from other groups. 
Within communities, this can become a complicated issue. Zakus and Lysack (1998), two Canadian health researchers, argue that health promotion practice that works from a zero-sum construction of power increases 'unhealthy' competition between people and decreases 'healthy' community capacity and cohesion. They also suggest that by empowering some at the expense of others in a zero-sum situation, health promoters are helping to break down the ties that hold a community together.

Communities are not homogeneous by their very nature consist of competing unrelated individuals and groups. Health promoters cannot, therefore, avoid empowering some while not others through the interventions and programmes that they deliver. The point raised by Zakus and Lysack (1998) does help to highlight the ethical and political dilemma of which some groups, at the expense of others, should get priority of the limited resources and assistance from the health promoters. This problem is confounded, however, if the group is unpopular or involved in illegal or unpalatable activities such as drug use or child abuse. The role of the health promoter is to be nonjudgmental but to be self-reflecting in their work.

There is another significant use of power, one that regards it not as fixed and finite, but as infinite and expanding. This is a 'non-zero-sum' form of power that s 'win/win,' since it is based on the idea that if any one person or group gains, everyone else gains also. Knowledge, trust, caring and other aspects of our social relationships with one another are examples of non-zerosum power. Perhaps unsurprisingly, health promoters often gravitate towards the non-zero-sum formulation. Indeed, much of the discourse of health promotion emphasising '...participation, caring, sharing and responsibility to others', addresses the exercise of power in which all people can benefit. Power is no longer seen as a finite commodity, such as wealth, or as the relative status and authority that this might confer.

Rather the non-zero-sum takes the form of relationship behaviours based on respect, generosity, service to others, a free flow of information and the commitment to the ethics of caring and justice. The role of the health promoter in this construction of power is to use these attributes to engender them in others, for example, through mentoring and counselling. This approach also transfers power between people by encouraging individuals to network and access information by themselves, in part by providing better access to resources, for example, through a website link. 
In practice, health promotion simultaneously involves zero-sum and non-zero-sum formulations of power. Power cannot be given, but communities can be enabled by health promoters to take power that they need from others. Health promoters must firstly identify their power base (access to resources and influence) and to understand how this can be appropriately acted upon to enable others to gain power through their endeavours. It is the relationship between the programme stakeholders which is empowering through the development of abilities and opportunities to seize control over the influences on the determinants of their health.

\section{Conclusion}

This book has been written to offer a convenient means to access and quickly understand the many terms, definitions and concepts used in health promotion theory and practice. It will provide a unique and invaluable companion to students and professionals and to anyone who is interested in and passionate about promoting health and enabling others to gain more control over its determinants.

\section{References}

ASH. (2012). Action on Smoking and Health. Accessed 20/1/2012. www.ash.org

Brown, P., Zavestoski, S., McCormick, S., Mayer, B., Morello-Frosch, R., \& Gasior, R. (2004). Embodied health movements: uncharted territory in social movement research. Sociology of Health \& II/ness, 26(1):50-80.

Christakis, N. A., \& Fowler, J.H. (2007). The Spread of Obesity in a Large Social Network Over 32 Years. New England Journal of Medicine, 357(4): 370-379.

Corcoran, N. (2013). Communicating health: strategies for health promotion. 2nd edition. (eds). London. Sage Publications Ltd.

Cornish, F. \& Campbell, C. (2009). The social conditions for successful peer education: A comparison of two HIV prevention programs run by sex workers in India and South Africa. American Journal of Community Psychology, 44(12): 123-135. 
Goodman, R., Speers, M., McLeroy, K., Fawcett, S., kegler, M., Parker, E., Rathgeb Smith, S., Sterling, T., \& Wallerstein, N. (1998). Identifying and defining the dimensions of community capacity to provide a base for measurement. Health Education and Behaviour, 25 (3): 258-278.

Israel, B. A., Checkoway, B., Schultz, A., \& Zimmerman, M. (1994). Health education and community empowerment: conceptualizing and measuring perceptions of individual, organisational and community control. Health Education Quarterly, 21(2): 149-70.

Kelly, J. A., St Lawrence, J. S., Stevenson, L. Y., Hauth, A. C., Kalichman, S. C., Diaz, Y. E., Brasfield, T. L., Koob, J. J., \& Morgan, M. G. (1992). Community AIDS/HIV risk reduction: the effects of endorsements by popular people in three cities. American Journal of Public Health, 82(11):1483-1489

Labonte, R., \& Laverack, G. (2008). Health Promotion in Action: From local to global empowerment. London. Palgrave Macmillan.

Laverack, G. (1999). Addressing the contradiction between discourse and practice in health promotion, unpublished $\mathrm{PhD}$ thesis, Deakin University, Melbourne.

. (2004). Health Promotion Practice: Power and Empowerment. London. Sage Publications.

Macmillan.

- (2014). $A$ to $Z$ of Health Promotion. Basingstoke. Palgrave

Lin, N. (2000). Inequality in Social Capital. Contemporary Sociology, 29: 78595.

Loue, S., Lloyd, L.S., \& O'shea, D.J. (2003). Community health advocacy. New York: Kluwer Academic/Plenum Publishers.

Minkler, M. (1989) Health Education, Health Promotion and the Open Society. An Historical Perspective. Health Education Quarterly, 16: 17-30.

Patients Association (2011) accessed 15/12/2011. http://www.patientsassociation.com 
Pescosolido, B. A. (1991). Illness Careers and Network Ties: A Conceptual Model of Utilization and Compliance. In Albrecht, G., \& Levy. J (eds). Advances in Medical Sociology. Greenwich, CT: JAI Press. Pp. 161-184.

Rissel, C. (1994). Empowerment: the holy grail of Health Promotion? Health Promotion International, 9(1): 39-47.

Smithies, J., \& Webster, G. (1998). Community Involvement in Health. Aldershot, England: Ashgate Publishing Ltd.

UNDP. (2002). Communication Behaviour Change Tools. EntertainmentEducation. New York. UNDP.

UNICEF. (2001). Effective Information, Education and Communication in Vietnam. UNICEF Hanoi, Vietnam.

UNICEF (2013) Peer education. http://www.unicef.org/lifeskills/index_12078.html. Accessed 21/1/2013.

Wallack, L, M., Dorfman, L., Jernigan, D., \& Makani, T. (1993). Media advocacy and public health. London. Sage publications.

Wallerstein, N. (1992). Powerlessness, empowerment and health. Implications for health promotion programs. American Journal of Health Promotion, 6(3): 197205.

Wallerstein, N., \& Bernstein, E. (1988). Empowerment Education: Freire's Ideas Adapted to Health Education. Health Education Quarterly, 15(4): 379-394.

Wasserman, S., \& Faust, K. B. (1994). Social Network Analysis: Methods and Applications. New York: Cambridge University Press.

Werner, D. (1988). Empowerment and health. Contact, Christian Medical Commission, 102: 1-9.

White, H. C. (1992). Identity and Control: A Structured Theory of Social Action. Princeton, NJ: Princeton University Press.

World Health Organisation. (1998). The Health Promotion Glossary. Geneva. WHO. 
. (1986). Ottawa Charter for Health Promotion.

Geneva. World Health Organisation.

(2005). The Bangkok Charter for Health Promotion

in a Globalized World. $6^{\text {th }}$ Global Conference on Health Promotion. Geneva. World Health Organisation.

Wright, E. R. (1997). The Impact of Organizational Factors on Mental Health Professionals' Involvement with Families. Psychiatric Services, 48: 921-27.

Zakus, J.D., \& Lysack, C. L. (1998). Revisiting community participation. Health Policy and Planning, 13(1): 1-12. 